\title{
Editorial: Triage in Conservation
}

\author{
Matt W. Hayward ${ }^{1,2}$ and J. Guy Castley ${ }^{3 *}$ \\ ${ }^{1}$ School of Environment, Natural Resources and Geography, College of Natural Sciences, Bangor University, Bangor, \\ United Kingdom, ${ }^{2}$ School of Environmental and Life Sciences, University of Newcastle, Callaghan, NSW, Australia, ${ }^{3}$ Griffith \\ School of Environment, Griffith University, Nathan, QLD, Australia
}

Keywords: conservation decision making, trade-off, conservation ethics, biodiversity value, conservation outcome

\section{Editorial on the Research Topic}

\section{Triage in Conservation}

Making good decisions remains an important aspect of conservation practice, and is typically underpinned by good science (Pullin et al., 2004; Cook et al., 2013; Roux et al., 2015). These decisions are informed by a variety of contexts and values but are also affected by uncertainty (Regan et al., 2005; Nicholson and Possingham, 2007). Conservation triage as a means to improve decision making and prioritize actions is a polarizing issue. Proponents see it as the most logical way of using limited conservation resources (Hobbs et al., 2003; Bottrill et al., 2008), whereas opponents reject the limitations imposed by society (notably governments) and seek adequate funding for the conservation of our natural heritage (Jachowski and Kesler, 2009). While triage has been used successfully to optimize the allocation of limited funds to conservation (Joseph et al., 2009), it is not universally accepted. In essence, this is much the same debate that is raging in broader conservation circles between the economic growth-based or humanitarian model of "new conservation," whereby society and economic growth via the ecosystem services biodiversity provides are used as drivers in an "it pays - it stays" system (Kareiva et al., 2012) and the traditional conservation model, where biodiversity is valued for its own sake and our responsibilities for intergenerational equity (Soule, 2013). New conservation leans heavily on economic neoliberalization, but the merits of this economic model are now being questioned (Tabb, 2003; Altvater, 2009; Merino et al., 2010). It could also be argued that proponents of conservation triage are promoting a realistic (defeatist) solution whereas opponents are being overly optimistic.

This collection of papers in the Triage in Conservation topic investigated these issues from a suite of different viewpoints. Several papers investigate the merits of employing triage methods for the conservation of specific issues. These papers emphasize the need to include complexities associated with local context into the decision making process. A central theme for a number of these papers was the prioritization of connectivity conservation efforts, such as Asian elephants Elephas maximus facing connectivity and human-wildlife conflict threats (Goswami and Vasudev), seeking funds via a "triage of means" strategy to improve $9,371 \mathrm{~km}^{2}$ of off-park connectivity for tigers Panthera tigris (Mondal et al.), shaping the development process to improve the conservation outcomes of linear transportation corridors in India (Habib et al.). Monitoring activities were also considered in the context of triage, as ongoing monitoring and review of population trajectories facilitates appropriate management and mitigation of pressures impacting these communities. As Wheeler et al. showed there was not widespread support for using triage to allocate monitoring effort in the Arctic. Linked to population level monitoring is the need to re-evaluate performance and the success of conservation interventions for threatened species, particularly if these species have been prioritized. However, Morrison et al. Wheeler et al. showed that common tools to assess population persistence (i.e., PVA) were often not repeatable nor reproducible, thereby undermining their utility in assessing conservation success. 
A number of the papers also addressed the philosophical elements of the triage debate. Buckley, Buckley illustrates the problem that conservation triage risks signaling to decisionmakers that some extinctions or population losses are acceptable, while Woodcock and Hayward introduce a new issue limiting the value of conservation triage in that the opportunity costs of conservation are likely to change in the future and thereby alter the calculations upon which original triage plans are based. As highlighted by the preceding summaries, conservation triage requires an understanding and integration of local contexts. In conservation, decisions are informed by values, need, available funding, etc. but Wilson and Law propose that conservation triage is essentially an ethical decision. The ethical side of hardnosed economic rationalization to determine which species to allow to go extinct was investigated in two articles. (Wilson and Law) invoke lessons from medical triage to attempt to bring together the proponents and opponents of conservation triage to conclude that a more diverse set of ethics be considered alongside more open communication of objectives and protocols while acknowledging risks is required for conservation triage to become more acceptable. Conversely, Vucetich et al. highlight that the entire basis of conservation triage on medical triage is ill-founded because the latter pre-supposes limited resource availability whereas the resources available for conservation are not fixed. Furthermore, there is acceptance of the moral value

\section{REFERENCES}

Altvater, E. (2009). Postneoliberalism or postcapitalism? The failure of neoliberalism in the financial market crisis. Dev. Dialogue, 51, 73-88. Available online at: http://www.daghammarskjold.se/publication/postneoliberalismbeginning-debate/

Bottrill, M. C., Joseph, L. N., Carwardine, J., Bode, M., Cook, C., Game, E. T., et al. (2008). Is conservation triage just smart decision making? Trends Ecol. Evol. 23, 649-654. doi: 10.1016/j.tree.2008.07.007

Cook, C. N., Mascia, M. B., Schwartz, M. W., Possingham, H. P., and Fuller, R. A. (2013). Achieving conservation science that bridges the knowledge-action boundary. Conserv. Biol. 27, 669-678. doi: 10.1111/cobi.12050

Hobbs, R. J., Cramer, V. A., and Kristjanson, L. J. (2003). What happens if we cannot fix it? Triage, palliative care and setting priorities in salinising landscapes. Aust. J. Bot. 51, 647-653. doi: 10.1071/BT02109

Jachowski, D. S., and Kesler, D. C. (2009). Allowing extinction: should we let species go? Trends Ecol. Evol. 24, 180. doi: 10.1016/j.tree.2008.11.006

Joseph, L. N., Maloney, R., and Possingham, H. P. (2009). Optimal allocation of resources among threatened species: a project prioritisation protocol. Conserv. Biol. 23, 328-338. doi: 10.1111/j.1523-1739.2008.01124.x

Kareiva, P., Marvier, M., and Lalasz, R. (2012). Conservation in the Anthropocene. Available online at: http://thebreakthrough.org/index.php/journal/past-issues/ issue-2/conservation-in-the-anthropocene/ (Accessed July 29 2014).

Merino, B. D., Mayper, A. G., and Tolleson, T. D. (2010). Neoliberalism, deregulation and Sarbanes-Oxley: the legitimation of a failed corporate governance model. Account Audit Account. J. 23, 774-792. doi: 10.1108/09513571011065871 of patients in medical triage, but society does not universally agree on the value of biodiversity, which lead them to conclude that conservation triage is an unhelpful concept (Vucetich et al.).

This Special Issue on Triage in Conservation yields examples of where triage can and has worked in conservation. Yet it also highlights practical and ethical problems with the concept of triage. It also offers a route forward to bridge the gap between conservation triage proponents and opponents. The debate around conservation triage remains, but continued communication between protagonists is the only way to move the concept to an appropriate conclusion.

\section{AUTHOR CONTRIBUTIONS}

All authors listed have made a substantial, direct and intellectual contribution to the work, and approved it for publication.

\section{ACKNOWLEDGMENTS}

Firstly, we extend our thanks to all the authors for contributing to the ongoing debate around conservation triage for the Special Topic. We would also like to thank all those who kindly reviewed manuscripts submitted and facilitating discussion on this topic. Enrico Di Minin kindly provided comments on this editorial.

Nicholson, E., and Possingham, H. P. (2007). Making conservation decisions under uncertainty for the persistence of multiple species. Ecol. Appl. 17, 251-265. doi: 10.1890/1051-0761(2007)017[0251:MCDUUF]2.0.CO;2

Pullin, A. S., Knight, T. M., Stone, D. A., and Charman, K. (2004). Do conservation managers use scientific evidence to support their decision-making? Biol. Conserv. 119, 245-252. doi: 10.1016/j.biocon.2003.11.007

Regan, H. M., Ben-Haim, Y., Langford, B., Wilson, W. G., Lundberg, P., Andelman, S. J., et al. (2005). Robust decision-making under severe uncertainty for conservation management. Ecol. Appl. 15, 1471-1477. doi: 10.1890/03-5419

Roux, D. J., Kingsford, R. T., McCool, S. F., McGeoch, M. A., and Foxcroft, L. C. (2015). The role and value of conservation agency research. Environ. Manage. 55, 1232-1245. doi: 10.1007/s00267-015-0473-5

Soule, M. (2013). The "New Conservation." Conserv. Biol. 27, 895-897. doi: $10.1111 /$ cobi.12147

Tabb, W. K. (2003). After neoliberalism? Monthly Rev. 55, 25-34. Available online at: https://monthlyreview.org/2003/06/01/after-neoliberalism/

Conflict of Interest Statement: The authors declare that the research was conducted in the absence of any commercial or financial relationships that could be construed as a potential conflict of interest.

Copyright (c) 2018 Hayward and Castley. This is an open-access article distributed under the terms of the Creative Commons Attribution License (CC BY). The use, distribution or reproduction in other forums is permitted, provided the original author(s) or licensor are credited and that the original publication in this journal is cited, in accordance with accepted academic practice. No use, distribution or reproduction is permitted which does not comply with these terms. 